\title{
ANALISA STRATEGI DALAM PEMASARAN (Studi Kasus pada Mie Gacoan di Karangtengah Kota Blitar)
}

\author{
Indria Guntarayana, Krisma Putri, Ratih Y Chuly \\ Universitas Islam Balitar Blitar \\ Email; indriaguntarayana@unisba.ac.id, krismakurniaptr@gmail.com, \\ ratihyusufchully@gmail.com
}

\begin{abstract}
The marketing strategy is an important thing for the sustainability of a business, therefore this research was conducted with the aim to find out the marketing strategy of the gacoan noodle culinary business in Karangtengah, Blitar City. Due to the many existing noodle restaurants, the competition in this business is getting tougher. Therefore, it is important for noodle restaurant business people to be able to provide satisfaction for consumers through quality products and services in order to compete in the noodle restaurant business. This study uses a qualitative method, for the data collection method used in this study is to conduct direct observation techniques or in-depth observations and interviews. The analysis tool is to use SWOT Analysis and SWOT Analysis Deming Cycle. Based on the analysis and discussion it can be concluded and described that the marketing strategy of Gacoan Noodles can be said to be good, Gacoan Noodles sells its products both Offline and Online.
\end{abstract}

Keywords: Marketing Strategy, Gacoan Noodles, SWOT

\begin{abstract}
ABSTRAK
Strategi pemasaran merupakan satu hal yang penting guna untuk keberlangsungan suatu usaha, oleh karena itu penelitian ini dilakukan dengan tujuan untuk mengetahui strategi pemasaran usaha kuliner mie gacoan di Karangtengah Kota Blitar. Dikarenakan Banyaknya restoran mie yang ada mengakibatkan persaingan dalam bisnis ini semakin ketat. Karena itu, penting bagi para pebisnis restoran mie untuk dapat memberikan kepuasan bagi konsumen melalui mutu produk maupun layanan agar dapat bersaing dalam bisnis restoran mie. Peneltian ini menggunkan metode Kualitatif, untuk metode pengumpulan data yang digunakan pada penelitian ini adalah dengan melakukan teknik pengamatan secara langsung atau observasi serta wawancara secara mendalam. Adapun alat analisanya adalah menggunakan Analisa SWOT dan Siklus Deming Analisis SWOT. Berdasarkan analisis dan pembahasan maka dapat disimpulkan serta diuraikan bahwa Strategi pemasaran Mie Gacoan sudah dapat dikatakan baik, Mie gacoan menjual produknya dengan cara Offline maupun Online.
\end{abstract}

Kata Kunci : Strategi Pemasaran, Mie Gacoan, SWOT

PENDAHULUAN

Dewasa ini pemasaran produk atau jasa dalam suatu perusahaan menjadi kendala tersendiri dikarenakan banyaknya usaha-usaha baru yang bermunculan 
dan tak jarang perusahaan tersebut menyediakan produk atau jasa yang serupa. Untuk mengatasi masalah tersebut sebuah perusahaan harus memperhatikan strategi pemsaran yang tepat agar tidak kalah dengan usaha-usaha lainnya, dalam menjalankan suatu strategi pemasaran diperlukan suatu pendekatan yang mudah dan juga fleksibel yang biasa disebut sebagai strategi bauran pemasaran (marketing mix). Dalam bahasa Indonesia marketing mix diartikan sebagai bauran pemasaran yang merupakan strategi pemasaran atau strategi promosi penjualan yang penting digunakan oleh suatu perusahaan dalam rangka menentukan harga jual yang bersifat unik, selain itu bauran pemasaran dibuat untuk menghasilkan pertukaran yang saling memberikan keuntungan untuk pasar yang dituju.

Aktivitas mempertukarkan tawaran yang bernilai kepada pelanggan dalam proses pemenuhan kebutuhan yang dilakukan oleh suatu perusahaan dapat dilakukan dengan mengkombinasikan empat variabel marketing yang dirasa sangat mendukung dalam mememenuhi target penjualan dan menentukan strategi pemasaran. Kombinasi keempat variabel dalam strategi pemasaran (marketing mix) adalah sebagai berikut: 1) Product (segala bentuk baik produk maupun jasa yang ditawarkan di pasar sasaran); 2) Price (sejumlah uang yang dikeluarkan oleh konsumen untuk mendapatkan barang yang ditawarkan oleh perusahaan); 3) Place (segala upaya yang dilakukan oleh perusahaan untuk mempermudah konsumen dalam memperolehh produk yang ditawarkan); dan 4) Promotion (bujukan atau dorongan yang dilakukan agar konsumen tertarik memebeli produk yang ditawarkan oleh perusahaan. Menurut Kotler \& Armstrong (1997:48), Marketing mix adalah suatu kumpulan variabel-variabel marketing yang dilakukan secara terpadu atau strategi pemasaran yang dilakukan secara bersamaan oleh perusahaan untuk mengejar target penjualan yang diinginkan dalam pasar sasaran.

Mie adalah produk pasta atau ekstrusi. Mie diperkirakan merupakan jenis makanan yang berasal dari daratan Cina. Hal tersebut dapat dilihat dari budaya bangsa Cina, jika diamati mie memiliki nilai simbolis karna disetiap perayaan ulang tahun mereka selalu menyajikan mie yang diyakini mewakili umur panjang dan jika memotong mie akan dipercaya mewakili nasib buruk (Juliano dan Hicks, 1990). Mie dapat pula dikategorikan sebagai salah satu komoditi pangan subtitusi karena dapat berfungsi sebagai bahan pangan utama pengganti pangan pokok.

Apabila kita pergi ke pasar maka akan sangat mudah untuk menemukan aneka jenis mie. Banyaknya jenis mie serta keanekaragamannya yang luas seringkali membuat konsumen mempertanyakan spesifikasi atauperbedaan dari setiap produk mie. Berbicara soal mie tentu bukan hal yang asing bagi banyak orang, bahkan dalam kegiatan sehari-hari mie dan produk sejenis mie telah dikenal dengan berbagai sebutan misalnya mie instan, mie telur, mie basah, mie bihun, sohun dan sebagainya. Lebih sederhananya beragam jenis mie ini ini dapat dikelompokkan berdasarkan bahan baku yang digunakan dalam proses pembuatan yaitu mie berbahan baku terigu dan non terigu.

Mie gacoan adalah mie pedas yang sedang booming dikalangan anak muda masa kini. Rasanya yang pedas dan memiliki beberapa level ini 
menggugah masyarakat (khususnya anak muda) untuk mencobanya. Selain menjual mie pedas, gacoan juga menjual beberapa snack seperti siomay, udang rambutan, udang keju, pangsit, dll.

Di daerah Blitar sendiri juga tidak hanya mie Gacoan saja yang menjual mie pedas. Mie gacoan memiliki beberapa pesaing seperti: mie judes dan mie iblis. Mie judes ini menjadi pesaing berat mie gacoan karena tempat penjualan yang hampir berdekatan.

Menurut Nastiti dan Martoatmodjo (2007), "Peningkatan kepuasan konsumen dapat dipengaruhi langsung oleh bauran pemasaran, apabila ualitas dari bauran pemasaran meningkat maka kepuasan konsumen terhadap prodak yang ditawarkan meningkat begitupun sebaliknya apabila bauran pemasaran menurun maka kepuasan konsumen juga akan menurun”. Dengan demikian, faktor-faktor dalam bauran pemasaran sangat mempengaruhi permintaan terhadap mie yang dijual. Selain bauran pemasaran terdapat faktor-faktor yang memepengaruhi permintaan, salah satu faktor tersebut adalah selera (Rahadja dan Manurung, 2002). Permintaan suatu barang dapat dipengaruhi oleh kebiasaan konsumen atau selera konsumen yang berubah-ubah dan berbedabeda. Selera konsumen yang berubah-ubah dapat disebabkan oleh perubahan umur, perubahan pendapatan, perubahan lingkungan, dan sebagainya. Salah satu makanan yang sampai saat ini menjadi selera hampir seluruh kalangan adalah mie. Mie diminati oleh semua masyarakat. Terlebih saat ini mie dengan rasa yang pedas sedang diminati oleh para anak muda jaman sekarang.

Untuk menjamin keberlangsungan suatu usaha yang banyak pesaing tentu dibutuhkan strategi promosi yang tepat. Variabel paling dominan terhadap keputusan pembelian oleh konsumen terhadap suatu produk atau jasa adalah promosi (Sukotjo dan Radi, 2010). Oleh sebab itu, dilakukannya penelitian ini dengan untuk mengidentifikasi bauran pemasaran yang terdiri dari kekuatan, kelemahan, peluang, da ancaman pemasaran, kemudian merumuskan alternative strategi pemasaran dan menentukan prioritas strategi yang dapat diterapkan dalam pemasaran usaha mie Gacoan Karangtengah, Kota Blitar. Berdasarkan latar belakang tersebut, dapat diidentifikasikan bagaimana strategi pemasaran Mie Gacoan? Serta apa kendala dalam pemasaran Mie Gacoan dan Bagaimana Solusinya?

\section{METODOLOGI PENELITIAN}

Dalam proses pelaksanaannya metode penelitian yang diguankan dalam penelitian ini adalah metode campuran yaitu menggunakan metode kualitatif dan kuantitatif. Digunakannya analisis kualitatif dalam penelitian ini adalah bertujuan untuk mengetahui dan memahami lingkungan perusahaan yang diteliti serta untuk mengetahui faktor kekuatan, kelemahan, peluang, dan ancaman yang dihadapi oleh perusahaan tersebut. Sedngkan penggunaan analisis kuantitatif dalam penelitian ini digunakan pada matriks IFE, matriks EFE, matriks IE, matriks Grand Strategy, matriks SWOT, dan juga Siklus Deming.

Untuk proses pengumpulan data, dalam penelitian ini metode yang digunakan adalah metode pengumpulan data dengan teknik pegamatan 
langsung atau observasi agar hasil data yang didapatkan sesuai dengan apa yang terjadi dilapangan. Selain menggunakan teknik observasi, dalam penelitian ini juga menggunakan teknik wawancara secara tidak terstruktur, teknik ini dimaksudkan untuk memeproleh jawaban yang real dari narasumber, jawaban yang dijawab secara spontan, jujur, serta memaparkan keadaan yang sebenarnya terjadi, selain itu teknik pengumpulan data dilakukan kepada pihakpihak yang dipercaya mengetahui situasi derta kondisi keadaan di kafe tersebut.

Tahap penyusunan strategi dalam penelitian dapat dilakukan melalui tiga tahapan kerja yaitu tahap memasukkan data (input), tahap pencocokan data, dan tahap pengambilan keputusan (David, 2009). Tahapan pertama dalam penyusunan strategi adalah tahap memasukkan data (input) dimana dalam penelitian ini tahap tersebut menggunakan matris EFE dan IFE. Setelah tahap input selesai tahap lanjutan dari penyususnan strategi adalah tahap pencocokan data, pada tahap ini manajemen focus pada pembuatan alternative strategi yang tepat dengan mecocokkan faktor eksternal dan faktor internal. Pada tahap ini matriks IE, matriks Grand Strategy dan SWOT digunakan sebagai alat analisis. Dan Siklus Deming untuk menentukan keputusan strategi. Setelah diketahui faktor kelemahan dan kekuatan melalui perencanaan strategi maka suatu manajemen perusahaan akan mampu mengurangi kelemahan yang dapat menjadi hambatan dan pada saat yang sama akan mampu memaksimalkan kekuatan untuk menunjang keberlangsungan usaha. Hal sama juga berlaku pada faktor tantangan dan ancaman, dimana pada saat tantangan mampu untuk diperkecil maka peluang yang ada justru mampu untuk diperbesar. Dari hal tersebut dapat dijadikan empat analisis strategi matriks SWOT untuk merumuskan dan merencanakan strategi pengembangan dari bisnis pada sector bisnis khususnya di bisnis Mie Gacoan tersebut.

\section{HASIL DAN PEMBAHASAN}

Mie Gacoan yang masih merupakan anak dari perusahaan PT Pesta Pora Abadi, yang merupakan resto mie yang memberikan price to quality (harga menentukan kualitas) terbaik dikelasnya. Mie Gacoan selalu menjaga dan membangun nilai-nilai perusahaan yaitu, Quality, Service, dan Cleanliness. Oleh karena itu, tidak heran jika kafe Mie Gacoan menjadi tempat bersantap mie terbaik bagi pelajar dan mahasiswa utamanya, dimana mereka bisa sekedar nongkrong, mengerjakan tugas, ngobrol santai, atau ber sua foto. Dengan menyajikan tempat yang mempunyai daya tarik tersediri bagi pengunjung, serta tersediannya berbagai fasilitas untuk menunjang kenyamanan pengunjung seperti: jaringan wifi, colokan listrik, music-musik terupdate, yang dijamin akan membuat customer atau pengunjung betah dan ingin kembali lagi. Suasana yang terencana dan sesuai dengan sasarannya akan dapat menarik pelanggan yang secara tidak langsung dapat merangsang minat konsumen untuk melakukan pembelian sekaligus merasa puas sehingga kembali mengulang-ulang pembelian (Tamher, Tabelessy, \& Tahapary, 2019).

Mie gacoan memiliki cabang di mana-mana. Salah satunya ada di Blitar, terletak di jalan Kalimantan No. 102, Karangtengah, Kec. Sananwetan, Kota 
Blitar, Jawa Timur. Mie gacoan masih memiliki cabang lagi di berbagai kota besar di Indonesia yaitu, Malang, Madiun, TulungAgung, Yogyakarta, Kediri, Solo, Bali, dll.

Mengusung konsep kafe, Mie Gacoan menawarkan tempat makan luas, bernuansa kekinian, cocok sekali untuk kalangan muda. Atmosfernya sangat mendukung untuk nongkrong dan yang tak kalah penting, tempat ini Instagramable. Sembari menunggu pesanan datang, pengunjung bisa menghabiskan waktu dengan pemainan yang disediakan pengelola.

Dari segi rasa, Mie Gacoan sebenarnya tak jauh beda dibanding mie pedas yang sering kita tahu. Konsumen bebas memilih tingkat kepedasan sesuai selera. Istilah yang diberikan untuk tiap levelnya cukup unik, mulai dari angel, setan, hingga iblis. Jadi yang tak tahan makanan pedas tak perlu khawatir. Cukup pesan mie angel yang disajikan tanpa cabai sama sekali. Sementara bagi yang ingin tantangan atau menambah selera makan, dipersilahkan menjajal level setan atau bahkan iblis. Perbedaan antara level setan dan iblis adalah, jika level setan itu hanya ada rasa gurih dan pedas, tetapi level iblis rasanya manis dan pedas.

Satu porsi Mie Gacoan terdiri dari pangsit goreng, mie dengan taburan daun bawang dan bawang goring, ayam cincang, plus cabe rawit. Biji-biji cabe tampak berhamburan, aura pedasnya terasa sangat kuat. Porsinya juga cukup banyak, dijamin puas. Resep untuk menetralisir pedas jangan lewatkan pangsit gorengnya. Isiannya berupa ayam cincang halus yang nikmat. Selain itu juga ada menu pendamping seperti macam-macam dimsum.

Selain bisa dimakan ditempat, mie gacoan juga bisa dipesan melalui aplikasi Grab. Dengan adaya aplikasi ini, para anak muda yang ingin membeli mie gacoan tidak harus datang ke tempatnya langsung. Kalian bisa order lewat aplikasi tanpa harus menunggu untuk mengantri.

\section{Analisis Swot Mie Gacoan}

Faktor strategis yang digunakan meliputi faktor kekuatan, kelemahan, peluang, dan faktor ancaman. Dari faktor-faktor tersebut yang masuk didalam faktor internal dimasukkan kedalam matriks yang disebut matriks faktor IFAS (Internal Strategic Factor Analisis Summary). Sedangkan yang termasuk di dalam faktor eksternal dimasukkan kedalam matrik yang disebut matriks faktor EFAS (Eksternal Strategic Factor Analisis Summary). Pada lingkungan internal (FAS) ditentukan faktor apa saja yang mendukung adanya kekuatan dan mengahambat adanya kelamahan. Lingkungan eksternal (EFAS) dengan ditentukan peluang dan ancaman. berikut hasil dari Analisa Swot Mie Gacoan :

\begin{tabular}{|c|c|c|c|}
\hline Factor-Faktor Strategi Internal & Bobot & Skor & Nilai Skor \\
\hline $\begin{array}{l}\text { STRENGHTS (kekuatan) } \\
\text { - Harga yang terjangkau } \\
\text { - Dapat dipesan melalui aplikasi } \\
\text { Grabfood } \\
\text { - Lokasi Strategis } \\
\text { - Menyediakan berbagai varian level }\end{array}$ & $\begin{array}{l}0.20 \\
0.20\end{array}$ & $\begin{array}{l}4 \\
5\end{array}$ & $\begin{array}{l}0.80 \\
0.50\end{array}$ \\
\hline
\end{tabular}




\begin{tabular}{|c|c|c|c|}
\hline $\begin{array}{l}\text { kepedasan Mie } \\
\text { - Memiliki area parker }\end{array}$ & 0.10 & 4 & 0.40 \\
\hline SUB TOTAL & 0.8 & & 3.7 \\
\hline $\begin{array}{l}\text { WEAKNESSES (kelemahan) } \\
\text { - Mudahnya Product untuk ditiru } \\
\text { - } \quad \text { Pifi yang kurang kencang } \\
\text { - } \quad \text { Hanya tersedia } 1 \text { kasir saja untuk } \\
\text { melayani konsumen } \\
\text { - Pelayanan lama }\end{array}$ & $\begin{array}{l}0.030 \\
0.020 \\
0.020 \\
0.030 \\
0.10\end{array}$ & $\begin{array}{l}3 \\
2 \\
2 \\
2\end{array}$ & $\begin{array}{l}0.090 \\
0.040 \\
0.040 \\
0.060 \\
0.20\end{array}$ \\
\hline SUB TOTAL & 0.2 & & 0.43 \\
\hline TOTAL & 1 & & 4.13 \\
\hline
\end{tabular}

Penjelasan dari tabel di atas yaitu kekuatan yang dimiliki Mie Gacoan adalah harga yang terjangkau dengan bobot 0.20 . Sedangkan kelemahan yang dimiliki Mie Gacoan adalah Pelayanan yang lama dengan bobot 0.10 .

\begin{tabular}{|c|c|c|c|}
\hline Faktor-Faktor Strategi Eksternal & Bobot & Skor & Nilai Skor \\
\hline $\begin{array}{l}\text { OPPORTUNESESS (peluang) } \\
\text { - Membuka cabang baru } \\
\text { - Mengadakan promo baik secara } \\
\text { online maupun offline } \\
\text { - Menambah varian Mie menjadi } \\
\text { lebih banyak } \\
\text { - Menguasai pasar } \\
\text { - Membuka lapangan pekerjaan }\end{array}$ & $\begin{array}{l}0.25 \\
0.15 \\
0.10 \\
0.10 \\
0.15\end{array}$ & $\begin{array}{l}4 \\
4\end{array}$ & $\begin{array}{l}1.25 \\
0.60 \\
0.40 \\
0.40 \\
0.60\end{array}$ \\
\hline SUB TOTAL & 0.75 & & 3.25 \\
\hline $\begin{array}{l}\text { THREATS (ancaman) } \\
\text { - Munculnya pesaing baru } \\
\text { - Harga bahan baku yang mengalami } \\
\text { kenaikkan } \\
\text { - Masyarakat bosan dengan product } \\
\text { jenis Mie } \\
\text { - Adanya usaha serupa (pesaing) } \\
\text { yang menjual produk serupa } \\
\text { dengan harga yang lebih murah, } \\
\text { produk yang sama, dan kualitas } \\
\text { yang lebih baik } \\
\text { - Peraturan Pemerintah dalam } \\
\text { bidang Ekonomi }\end{array}$ & $\begin{array}{l}0.050 \\
0.025 \\
0.025 \\
0.10 \\
0.050\end{array}$ & $\begin{array}{l}3 \\
2 \\
2 \\
3\end{array}$ & $\begin{array}{c}0.15 \\
0.050 \\
0.050 \\
0.30\end{array}$ \\
\hline SUB TOTAL & 0,25 & & 0.7 \\
\hline TOTAL & 1 & & 3.95 \\
\hline
\end{tabular}


Dari tabel diatas menunjukkan bahwa peluang yang dimiliki oleh Mie Gacoan adalah membuka cabang baru dengan bobot 0.25. Sedangkan faktor ancaman yang dimiliki oleh Mie Gacoan adalah adanya usaha serupa (pesaing) yang menjual produk serupa dengan harga yang lebih murah, produk yang sama, dan kualitas yang lebih baik dengan bobot 0.10 .

\section{KEKUATAN ( strength )}

Harga : indikator dari S yang nilainya tertinggi pertama adalah harga (nilai =5) karena harga yang ditawarkan sesuai dengan kantong masyarakat Kota Blitar. Selain itu letak yang strategis sangat mendukung promosi di Mie Gacoan.

\section{KELEMAHAN ( weakness )}

Pelayanan : Pelayanan yang lama disebabkan karena kurangnya tenaga di bagian dapur sehingga membutuhkan waktu yang lama untuk memasak mie sedangkan pelanggan terus berdatangan.

\section{Diagram Analisis SWOT}

Kuadran SWOT diperoleh dari rumus untuk mengetahui posisi dan kondisi perusahaan berada pada posisi kuadran. Rumus yang digunakan, sebagai berikut :

$$
\begin{aligned}
& \mathrm{X}=\frac{\text { Nilai } S-\text { Nilai } W}{2}=\frac{3.270-0.430}{2}=1.635 \\
& \mathrm{Y}=\frac{\text { Nilai } O-\text { Nilai } T}{2}=\frac{3.250-0.70}{2}=1.275
\end{aligned}
$$

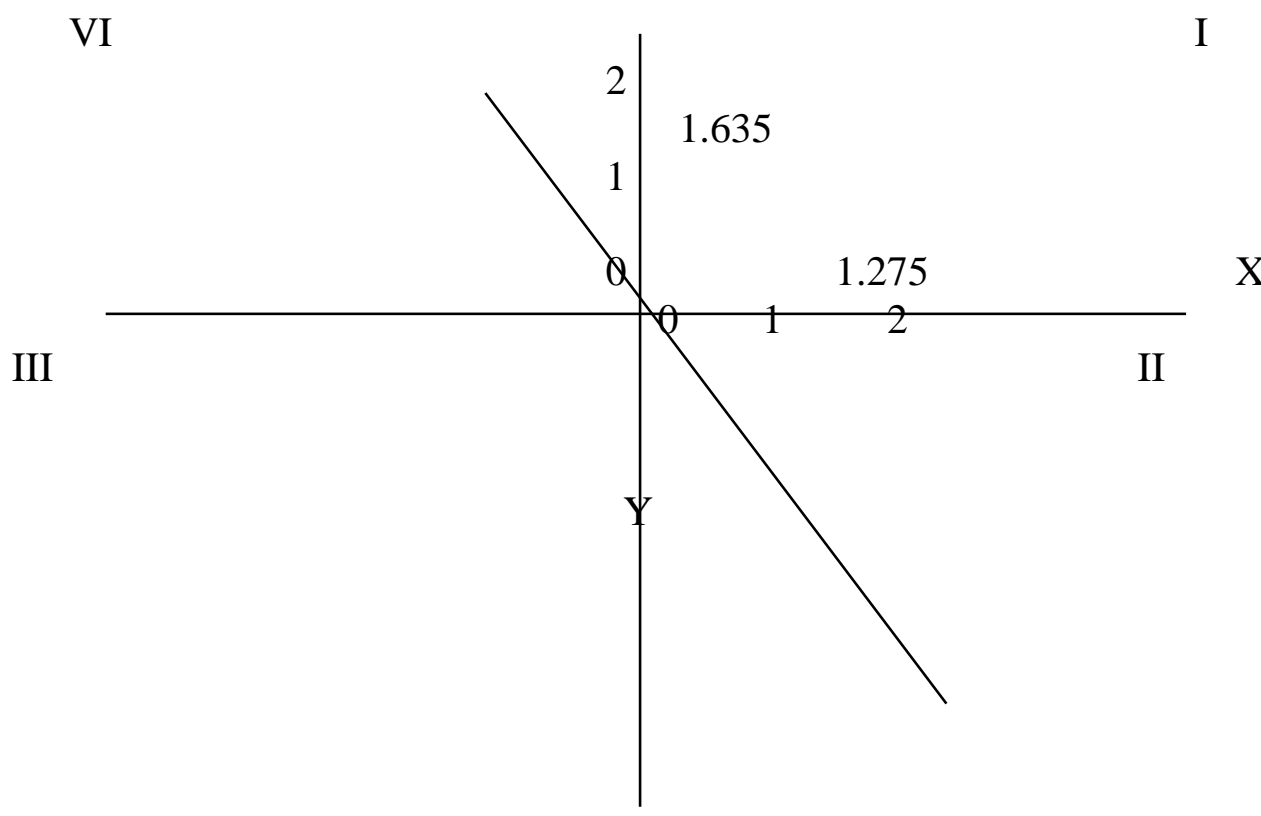




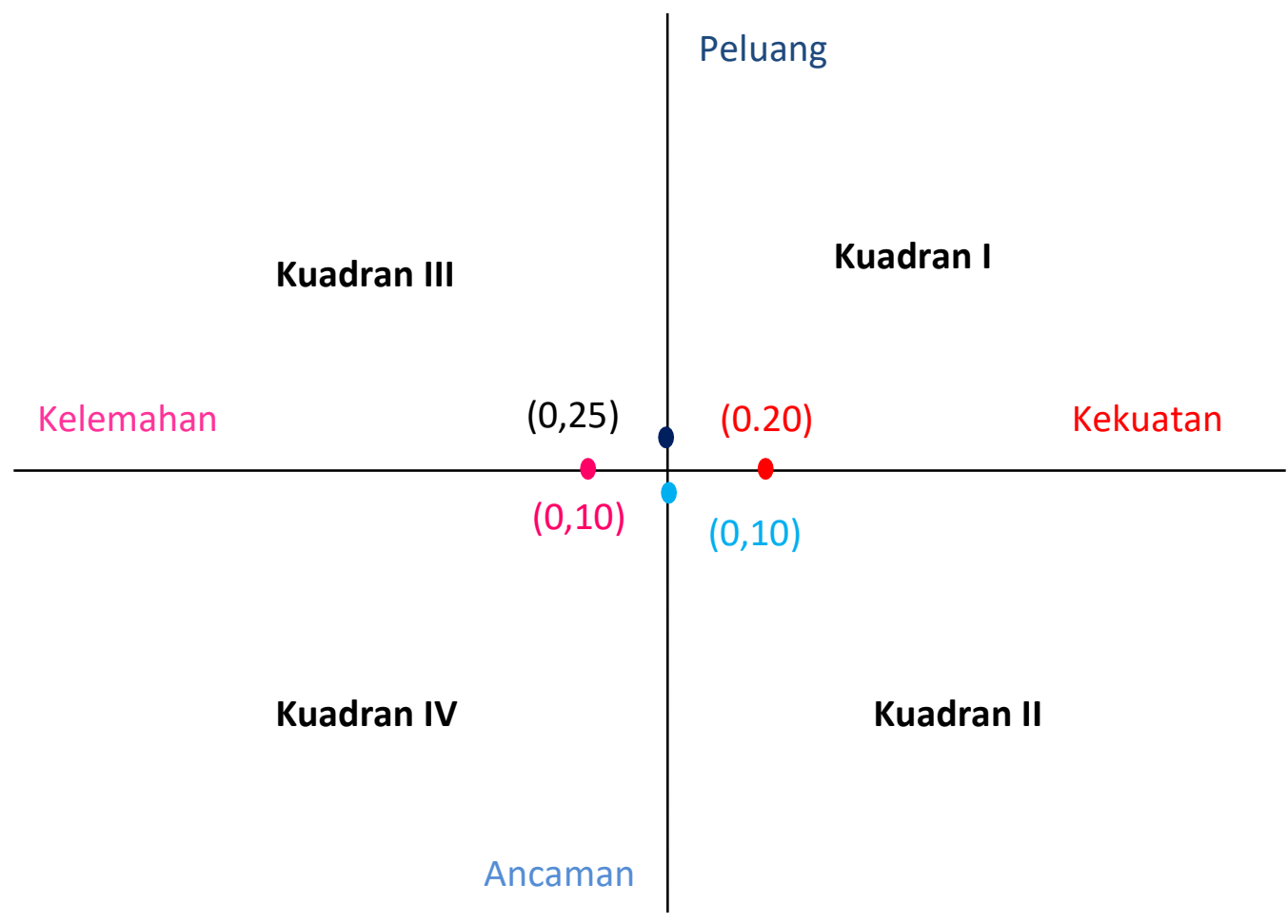

\section{Model Matrik Analisis Swot}

Berikut disajikan beberapa hasil identifikasi dari berbagai faktor yang menjadi landasan di dalam proses menyusun strategi pengembangan produkproduk bisnis maupun jasa di suatu daerah dalam bentuk model matriks analisis SWOT. Sebagai seuatu analisis situasi yang mengkaji kondisi faktorOfaktor eksternal dan kondisi internal dari setpa obyek dan daya tarik bisnis suatu daerah analisis SWOT membandingkan antara faktor kekuatan (strength) dan faktor kelemahan (weakness) pengembangan bisnis yang masuk dalam faktor internal, dengan faktor eksternal yaitu faktor peluang (opportunity) dan faktor ancaman (threats).

\begin{tabular}{|c|c|c|c|}
\hline \multirow[t]{5}{*}{ INTERNAL } & \multicolumn{3}{|c|}{ EKSTERAL } \\
\hline & $\begin{array}{l}\text { Identifikasi } \\
\text { Faktor }\end{array}$ & Opportunity (O) & Threats $(\mathrm{T})$ \\
\hline & & $\begin{array}{l}\text { Tentukan faktor } \\
\text { peluang }\end{array}$ & $\begin{array}{ll}\text { Tentukan } & \text { Faktor } \\
\text { Ancaman } & \end{array}$ \\
\hline & Strength $(\mathrm{S})$ & $\mathrm{S}$ vs $\mathrm{O}$ & S vs T \\
\hline & $\begin{array}{l}\text { Tentukan } \\
\text { Faktor } \\
\text { Kekuatan }\end{array}$ & $\begin{array}{l}\text { Dengan harga yang } \\
\text { terjangkau dan } \\
\text { membuka cabang } \\
\text { baru di daerah lain, } \\
\text { Mie Gacoan dapat } \\
\text { menambah }\end{array}$ & $\begin{array}{l}\text { Harga yang terjangkau } \\
\text { dan Adanya usaha } \\
\text { serupa (pesaing) yang } \\
\text { menjual produk serupa } \\
\text { dengan harga yang } \\
\text { lebih murah, produk }\end{array}$ \\
\hline
\end{tabular}




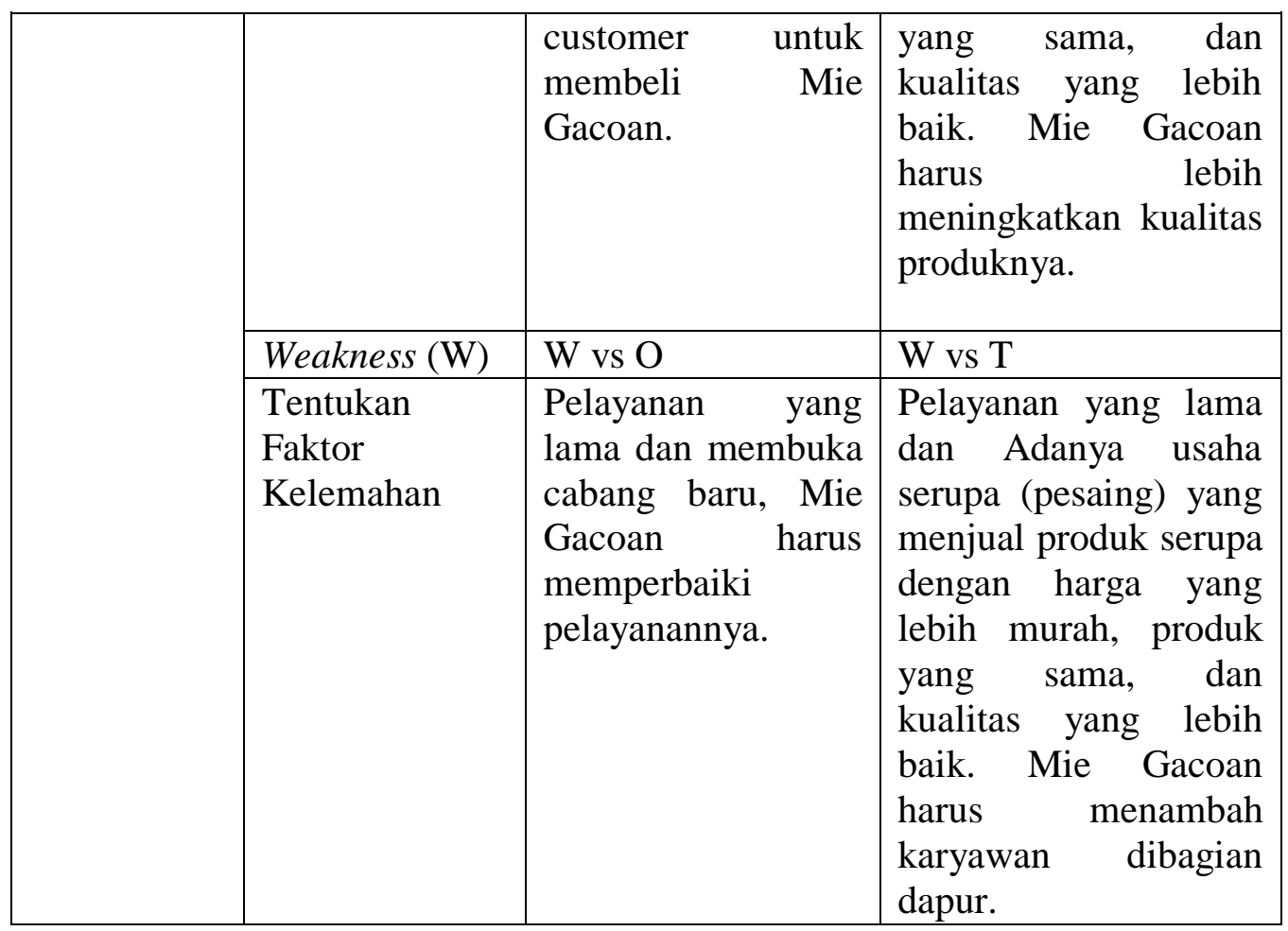

\section{Hasil Temuan Siklus Deming}
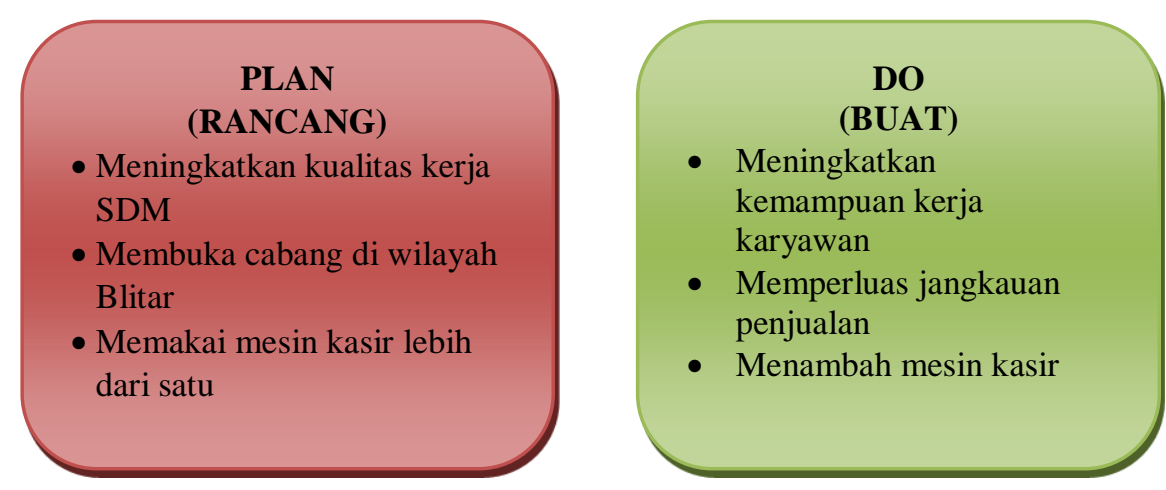

\section{CHECK \\ (SEMAK)}

- Hasil kerja karyawan tidak sesuai harapan

- Penambahan biaya pembukaan cabang baru

- Karena mesin kasir hanya satu membuat antrian pemesanan menjadi panjang dan lama

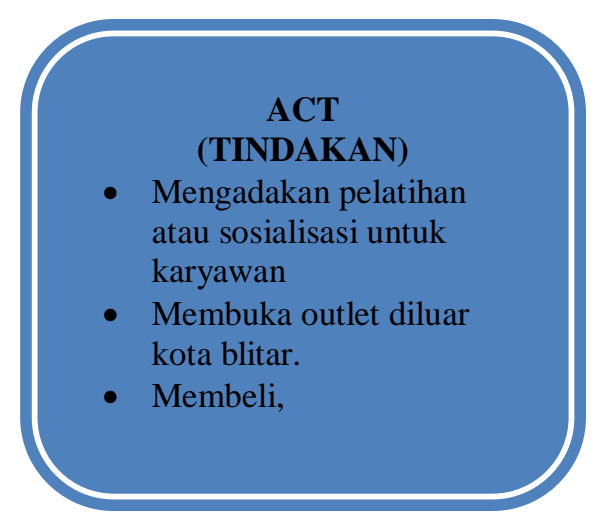




\section{KESIMPULAN DAN SARAN}

Kesimpulan

Berdasarkan hasil analisis dan pembahasan di atas maka dapat ditarik kesimpulan sebagai berikut:

1. Strategi pemasaran Mie Gacoan sudah dapat dikatakan baik, Mie gacoan menjual produknya dengan cara Offline maupun Online dan membuat Restoran menjadi instragramebel untuk memikat konsumen untuk datang.

2. Hambatan yang mungkin akan dialami oleh Mie Gacoan yaitu : adanya usaha serupa (pesaing) yang menjual produk serupa dengan harga yang lebih murah, produk yang sama, dan kualitas yang lebih baik.

\section{Saran}

Untuk menjaga agar Mie Gacoan selalu di datangi oleh pembeli atau para konsumennya, maka Mie Gacoan harus memperbaiki serta meningkatkan kualitas pelayanannya agar menjadi lebih baik lagi kedepannya.

\section{DAFTAR PUSTAKA}

Abshier, et al. 1994. Shopping Center - Niches Marketing "How to Find and Profit from Market Segment", International Council of Shopping Center. New York: United State of America.

Adipoetra, Wilhelmina. 2004. Upaya Peningkatan Kinerja Pemasaran dengan Konsep Marketing Strategy Making Process melalui Kreativitas Strategi dan Pembelajaran Organisasional. Tesis, Program Magister Manajemen, Program Pascasarjana. Semarang: Universitas Diponegoro.

Bressler, Martin S. 2012. How Small Business Master The Art of Competition Through Superior Competitive Advantage, Journal of Management and Marketing Research.

Buckley R. 2003. Partnership in ecotourism: Australian political frameworks. International Centre for Ecotourism Research 6(2): 75-83.

Engel, James FR, Blackwell, Paul M. 1994. Perilaku Konsumen. Edisi 6. FX Budiyanto, Penerjemah. Jakarta: PT. Binarupa Aksara.

Fatonah, Siti. 2009. Pengaruh Bauran Pemasaran dan Orientasi Pasar Terhadap Keunggulan Bersaing Dalam Meningkatkan Kinerja Pemasaran Pada Perusahaan Batik di Surakarta. Jurnal Ilmu Ekono idan Manajemen, vol 6, no.1.

Foster, Bob. 2011. Pengaruh Kinerja Bauran Penjualan Eceran (Retailing Mix) dan Hubungan Pelanggan (Customer Relationship) Terhadap Pembentukan Ekuitas Merek, Serta Dampaknya Terhadap Keunggulan Bersaing dan Loyalitas Pelanggan Department Store di DKI Jakarta. Jurnal Pendidikan Manajemen Bisnis, vol 10, no. 19.

Fraser, Kim A . CDM. 1991. Marketing Small Shopping Centres "How to Increase Retail Traffic and Sales", International Council of Shopping Centres. New York: United State of America.

Goi, Chai Lee. 2009. A Review of Marketing Mix: 4P or More ?. International Journal of Marketing Studies, vol. 1, no. 1.

Gujarati D. 2006. Dasar-Dasar Ekonometrika. Jakarta: Erlangga.

Hendarto KA. 2003. Bauran pemasaran pada jasa ekowisata. Jurnal Ilmiah 
Kesatuan 4(1-2):1-31.

Hidayat R. 2009. Pengaruh kualitas layanan, kualitas produk dan nilai nasabah terhadap kepuasandan loyalitas nasabah Bank Mandiri. Jurnal Manajemen dan Kewirausahaan 11(1): 59-72.

Hurriyati R. 2010. Bauran Pemasaran dan Loyalitas Konsumen. Jakarta: CV Alfabeta.

Iyangjaya AP. 2013. Strategi pemasaran pariwisata Kabupaten Jepara. Jurnal Penelitian Ilmu Pemerintahan 2(4): 1-9.

Joehastanti. 2012. Strategi pemasaran wisata alam untuk meningkatkan kunjungan wisatawan di kawasan wisata Kabupaten Kediri. Jurnal Ilmu Manajemen 1(2): 61-73.

Karta NPA, Suarthana IKP. 2014. Strategi komunikasi pemasaran ekowisata pada destinasi wisata Dolphin Hunting Lovina. Jurnal Manajemen Strategi Bisnis dan Kewirausahaan 8(1):45-51.

Kesrul M. 2003. Penyelenggaraan Operasi Perjalanan Wisata. Jakarta: Gramedia.

Khan, Shireen. 2011. Marketing Mix Strategy Adaptation : A Retail Organisation's Response to The Global Economic Downturn. Thesis. Master of Tehnology Marketing. Cape: Cape Peninsula University of Technology.

Kotler P. 2006. Principles of Marketing. 10th edition. New Jersey: Prentice Hall Upper Sadle River.

Kotler P. 2011. Manajemen Pemasaran. Edisi 14.Jakarta: PT. Indeks Kelompok Gramedia

Khomsan, Ali, dkk. 2003. Rekayasa Sosial dan Pengembangan Teknik Edukasi Peningkatan Diversifikasi Konsumsi Pangan Pokok. Laporan Akhir. Fakultas Pertanian-IPB. Bogor.

Suendro, Ginanjar. 2010. Analisis Pengaruh Inovasi Produk Melalui Kinerja Pemasaran UntukMencapai Keunggulan Bersaing Berkelanjutan (Studi Kasus Pada Industri Kecil dan Menengah Batik Pekalongan). Tesis, Program Magister Manajemen, Program Pascasarjana. Semarang: Universitas Diponegoro.

Supranoto, Mieke. 2009. Strategi Keunggulan Bersaing Produk Melalui Orientasi Pasar, Inovasi, dan Orientasi Kewirausahaan Dalam Meningkatkan Kinerja Pemasaran ( Studi Empiris Pada : Industri Pakaian Jadi Skala Kecil dan Menengah di Kota Semarang). Tesis, Program Magister Manajemen, Program Pascasarjana. Semarang: Universitas Diponegoro.

Tamher, E. R., Tabelessy, W., \& Tahapary, G. (2019). Atmosfer Cafe Pengaruhnya Terhadap Kepuasan Dan Loyalitas Pelanggan Cafe Pasir Putih Di Kota Ambon. Jurnal Soso-Q, 7(2). 